\title{
The Physicians' Attitudes and Barriers to Proactive Sexual History Taking During Comprehensive Geriatric Assessment
}

\author{
(1) Doha Rasheedy, (1D Mohamed Mortada \\ Ain Shams University Faculty of Medicine, Department of Geriatrics and Gerontology, Cairo, Egypt
}

\begin{abstract}
Objective: The purpose of this study was to assess the geriatricians' attitudes and perceived barriers to proactive sexual history taking during comprehensive geriatric assessment (CGA).

Materials and Methods: A self-administrated survey was delivered to 150 geriatricians in Cairo, Egypt. Fifty-six were returned (response rate $=37.33 \%$ ). The demographic data, attitudes, and barriers to discussing sexuality were probed.

Results: All the participants thought that sexual history should be taken during the first office visit as a part of the CGA process, however, 13 (23.2\%) participants have never obtained a sexual history and 43 (76.78\%) obtained it out of necessity. None of the respondents obtained sexual history on a routine basis. The reported barriers included fear of the patients' impressions, presence of major comorbid health problems, and lack of privacy during interview. The physicians' gender and marital status did not affect their attitudes towards proactive sexual history. However, the patients' educational level and social status can affect physicians' attitudes towards sexual history.
\end{abstract}

Conclusion: This study highlights both the lack of proactive sexual history taking and the main related barriers in geriatric practice in Egypt.

Keywords: Culturally competent care, geriatric assessment, geriatricians, health services for the aged, sexual health

\section{Introduction}

Sexuality is an integral aspect of emotional and physical wellbeing across lifespan. For older adults, it is an important contributing factor to the quality of life and successful ageing (1). Yet, it remains a neglected issue by both the patient and the physician during health assessment $(2,3)$.

Against the popular belief that older adults lack sexual desires or that they are physically unable to perform (2), many adults remain sexually active into later life (3), even though many age related physiological changes, comorbid medical disorders, medications, and psychosocial factors might interfere with the sexual performance among older patients (4).

Yet, sexual problems are common among both elderly men and women. The prevalence of sexual dysfunction in men and women aged $40-80$ years, across 29 countries was $28 \%$ and $39 \%$, respectively (5).
In Egypt, men with moderate erectile dysfunction (ED) comprised $10.3 \%$ and those with complete ED were 13.2\%. Twenty-six percent of men with complete ED were in their 50 s, $49 \%$ of them in their 60 s and $52 \%$ were 70 years or older (6). Data regarding sexual dysfunction in elderly Egyptian women is lacking.

In order to early detect and intervene with sexual problems, the sexual history taking is becoming an indispensable part of the comprehensive geriatric assessment (CGA). However, many geriatricians feel uncomfortable to incorporate sexual history into patient assessment (7). In the United States, only 38\% of men and $22 \%$ of women had discussed sex with a physician since age 50 (8).

Several obstacles can make sexual history taking a challenge for clinicians. These obstacles include clinician, patient, and setting related barriers (9). One of the most important physician related barrier to sexual history taking is the inadequate or insufficient

Address for Correspondence: Doha Rasheedy, Ain Shams University Faculty of Medicine, Department of Geriatrics and Gerontology, Cairo, Egypt E-mail: doharasheedy@yahoo.com ORCID: orcid.org/0000-0002-3767-1516

Received: Sep 02, 2019 Accepted: Nov 26, 2019

Cite this article as: Rasheedy D, Mortada M. The Physicians' Attitudes and Barriers to Proactive Sexual History Taking During Comprehensive Geriatric Assessment. Eur J Geriatr Gerontol 2019;1(3):94-100

๑Copyright 2019 by the Academic Geriatrics Society / European Journal of Geriatrics and Gerontology published by Galenos Publishing House. 
training in sexual health (10). The embarrassment, fear of being insensitive and cultural issues may also hamper proactive sexual history (11).

The attitudes of geriatricians towards discussing sexuality in Egypt may be affected by cultural sensitivity, but other administrative barriers should not be underestimated e.g. inadequate training, time restraint or privacy issues.

The aim of this study was to assess the Egyptian geriatricians' attitudes and barriers to taking a proactive sexual history in clinical practice.

\section{Materials and Methods}

The study methodology was reviewed and approved by the Research Review Board of the Ain Shams University Faculty of Medicine, Department of Geriatrics and Gerontology (GG-ASU2019/18a).

Fifty-six geriatricians (consultants, specialists, and registrars) responded to a self-administered closed-question survey related to sexual history taking during the CGA. The participants were included in the study as a conveniencebased sample of geriatricians in Egypt. The total number of geriatricians registered in the Egyptian medical syndicate is 150 with about (30) 20\% of them working abroad, 12 working in the ministry of health, and the rest are working in university hospitals.

The survey was distributed through online form and through hand-to-hand approach. Those hand-delivered were placed in an opaque envelope to ensure anonymity.

The authors created the questions based on previous researches related to this issue. Part I recorded personal information. The participants were asked about their age, gender, years of experience, marital status, and if they consider themselves as conservative persons. Part II recorded the attitudes and barriers to obtaining sexual history during CGA.

The participants were asked if they routinely took a sexual history and the reasons, if any, for not obtaining it routinely from elderly patients e.g. lack of time during office assessment, lack of training, embarrassment, or not knowing how to manage patients' concerns. Moreover, the respondents opinion whether sexual history taking should become a routine practice during CGA was obtained (Appendix 1).

\section{Statistics}

The collected data were coded, tabulated, revised and statistical analyzed using SPSS program-version 16 (SPSS Inc., Chicago, IL, USA). Data were analyzed using counts and proportions. The qualitative variables were compared by using the chi-square test. Independent samples t-tests were used to explore gender differences in mean age. ANOVA test was used to compare age between different staff categories. A $p$ value less than 0.05 was considered statistically significant. Regression analysis for predictors of never taking a sexual history was performed.

\section{Results}

In total, 56 of the 150 Egyptian geriatricians responded to the survey with a response rate of $37.33 \%, 15(26.8 \%)$ were males and 41 (73.2\%) were females. They included 15 (26.8\%) registrars, 17 (30.4\%) specialists and $24(42.9 \%)$ consultants. Their mean age was $26.26 \pm 0.96,30.7 \pm 3.15,40.45 \pm 3.48$ years, respectively $(p<0.0001)$ (Table 1$)$.

Many of the participants worked in public hospitals. Although, all the participants thought that sexual history should be taken during the first office visit as a part of CGA, none of them routinely did so (Table 1).

Eighteen (32.14\%) of the geriatricians obtained sexual history only when the patient had a certain sexual issue, 30 (53.71\%) of them obtained sexual history when the patient had a related health problem, and $13(23.2 \%)$ of them have never obtained a sexual history (Table 1).

Surprisingly, eighteen (32.14\%) of our sample thought that sexual problems were uncommon among older adults, and 19 $(33.95 \%)$ reported that older adults are not sexually active. Only one third of our sample considered themselves properly trained to address sexual issues. None of the registrars considered themselves adequately trained to address sexual concerns. Only $27 \%$ of the respondents reported that their supervisors encouraged them to obtain proactive sexual history (Table 1).

The most common reported barriers to proactive sexual history taking were the fear of the patients' impression, the presence of major comorbid health problems, and the lack of privacy during the interview in $76.8 \%, 71.4 \%$, and $71.4 \%$ of the responses, respectively (Table 1 ).

Despite being more trained, more consultants viewed low education and low social class as major obstacles for taking sexual history during CGA (Table 1). Likewise, female geriatricians reported more difficulties when addressing sexual problems in patients with low education or low social class compared to males. Otherwise, there was no gender difference in other perceived barriers (Table 2).

Using a regression analysis, being a registrar and the underestimation of sexual problem among older adults were the independent predictors for never obtaining a sexual history during CGA (Table 3).

\section{Discussion}

In Egypt, while elderly patients seek treatment for a variety of health related problems, they remain very hesitant when 
Appendix 1: The questionnaire form applied to the participants

Demographic data:

- Age

- Gender: Male $\square$ Female $\square$

- Marital status Married $\square$ Single $\square$ Divorced $\square$

- Place of practice Urban $\square$ Rural

Private sector $\square$ Public sector $\square$

- Current position Registrar $\square$ Specialist $\square$ Consultant $\square$

- Do you consider yourself conservative Yes $\square$ No $\square$

When performing a comprehensive geriatric assessment:

- When do you obtain sexual history:

0 As a routine

o I obtain sexual history, only if there was a presumed association of Sexual History with Current Health Problems.

o Only if the patient enquires about a certain concern

o Never obtained sexual history from my patients

- Do you think sexual problems are common among elderly patients?

- Do you think that you have enough information about sexual health in older adults?

- Did you receive adequate training to comprehensively address sexual concerns?

- Do your supervisors recommend you to take sexual history from your elderly patients?

- Do you think sexual history taking should be routine practice during CGA?

- Do you think elderly patients are less sexually active?

Why don't you routinely obtain sexual history? (the barriers)

1. I don't have enough time during the daily practice Yes $\square$ No $\square$

2. I don't consider it appropriate Yes $\square$ No

3. I think my patient may consider it inappropriate Yes $\square$ № $\square$

4. I think elderly patients have little interest in sexuality Yes $\square$ No $\square$

5. I think elderly patients have major health concerns that is more important than sexuality

Yes $\square$ No $\square$.

6. I think lack of privacy during interview interferes with sexual history taking Yes $\square$ No $\square$

7. I am concerned about not being able to cope with the issues raised Yes $\square$ No $\square$

In your opinion, which of the previously mentioned barriers prevented you to routinely obtain sexual history?

$1 \square 2 \square 3 \square 4 \square 5 \square 6 \square 7 \square$

Do you find it more difficult to obtain sexual history from patients of opposite gender? Yes $\square$ No

Do you find it more difficult to obtain sexual history from patients of low educational level? Yes $\square$ No $\square$

Do you find it more difficult to obtain sexual history from patients of low social status? Yes $\square$ No $\square$ 


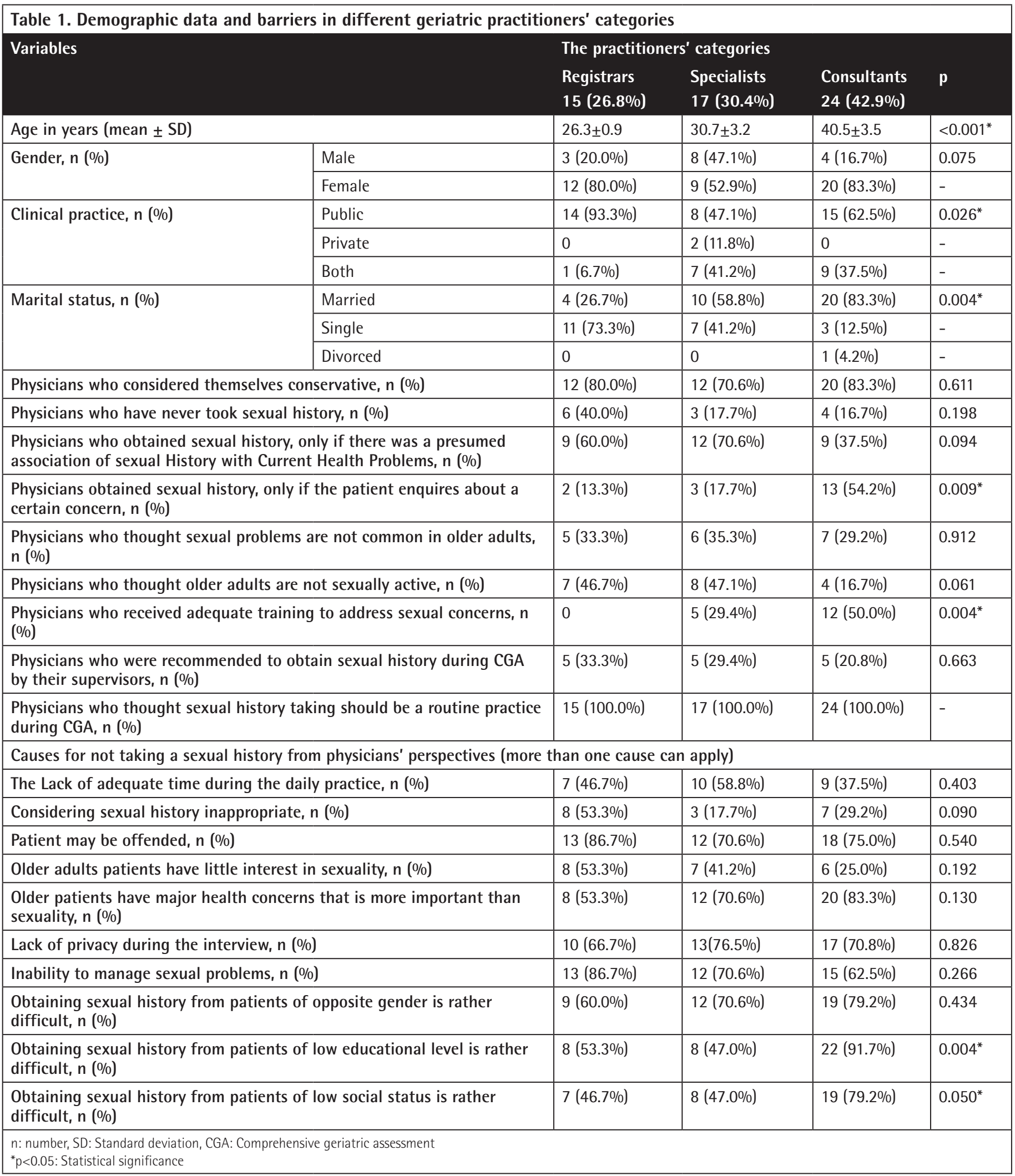

seeking medical help for a sexual problem. This may be due to embarrassment or perceiving sexual problems as normal part of ageing process. Thus, it is mandatory for geriatricians to become proactive when approaching sexual issues with their patients.
Unfortunately, many geriatricians feel ill at ease to take sexual history during heath assessment; many factors might contribute to this discomfort (7). 
Table 2. Gender difference in physicians' attitudes and perceived barriers

Age years (mean \pm SD)

The type of clinical practice, $\mathrm{n}(\%)$

$33.0 \pm 7.0$

$31(73.2 \%)$

Pricheath care service

Marital status of the participants $n(\%)$

Martal status of the participants $n(\%)$

Physician category, n (\%)

\begin{tabular}{|l|l|} 
Public health care service \\
\cline { 2 - 2 } Private health care service \\
\hline Both \\
\hline Married \\
\hline Single \\
\hline Divorced \\
\hline Registrars \\
\hline Specialists \\
\hline Consultants \\
\hline
\end{tabular}

Physicians who have never took sexual history, $\mathrm{n}(\%)$

Physicians who obtained sexual history, only if there was a presumed association of sexual history with current health problems, $\mathrm{n}(\%)$

Physicians obtained sexual history, only if the patient enquires about a certain concern, $\mathrm{n}(\%)$

Physicians who thought sexual problems are not common in older adults, $\mathrm{n}(\%)$

Physicians who thought older adults are not sexually active, $\mathrm{n}(\%)$

Physicians who received adequate training to address sexual concerns, $\mathrm{n}(\%)$

Physicians who thought sexual history taking should be a routine practice during CGA, $n(\%)$

Causes for not taking a sexual history from physicians' perspectives (more than one cause can apply)

The Lack of adequate time during the daily practice, $\mathrm{n}(\%)$

Considering sexual history inappropriate, $\mathrm{n}(\%)$

Patient may be offended, $\mathrm{n}(\%)$

Older adults patients have little interest in sexuality, $\mathrm{n}(\%)$

Older patients have major health concerns that is more important than sexuality, $\mathrm{n}(\%)$

Lack of privacy during the interview, $\mathrm{n}(\%)$

Inability to manage sexual problems, $\mathrm{n}(\%)$

Obtaining sexual history from patients of opposite gender is rather difficult, $\mathrm{n}(\%)$

Obtaining sexual history from patients of low educational level is rather difficult, $\mathrm{n}(\%)$

Obtaining sexual history from patients of low social status is rather difficult, $\mathrm{n}(\%)$

n:number, SD: Standard deviation, CGA: Comprehensive geriatric assessment

${ }^{*} p<0.05$ : Statistical significance

\begin{tabular}{|c|c|c|c|c|c|}
\hline Variables & $\begin{array}{l}\text { Standardized } \beta \\
\text { coefficients }\end{array}$ & SE & $\mathbf{p}$ & Odds ratio & $\begin{array}{l}95 \% \mathrm{Cl} \text { for Odds } \\
\text { ratio }\end{array}$ \\
\hline Female gender & 2.4 & 1.5 & 0.105 & 0.1 & $0.0-1.4$ \\
\hline Being single & 21.7 & 4.0 & 1.000 & 0.9 & $0.1-6.0$ \\
\hline Inadequate training & 18.6 & 1.9 & 0.999 & 0.1 & $0.0-0.7$ \\
\hline Underestimating sexual problems in older adults & 3.5 & 1.5 & $0.019^{*}$ & 1.3 & $1.1-1.9$ \\
\hline Considering older adults as sexually inactive & 0.6 & 1.5 & 0.692 & 1.1 & $0.1-16.1$ \\
\hline Constant & -54.4 & 4.4 & 0.999 & - & - \\
\hline
\end{tabular}


To our knowledge, this is the first study to address the Egyptian geriatricians' attitudes and barriers to proactive sexual history in clinical practice. Moreover, it is the first study to assess geriatricians' attitudes towards sexual history taking as part of the CGA in an Arab country.

Arab geriatricians may exhibit negative attitude towards sexual history taking as discussing sexuality is considered a cultural taboo. The cultural bias may exhibit prejudice against sexual orientation and sexually transmitted diseases. Yet, other administrative barriers should not be underestimated when addressing barriers to sexual health assessment.

In this survey, all interviewed geriatricians agreed that taking a sexual history should become a routine practice during CGA. Yet, $23 \%$ of them have never taken one, and about $70 \%$ did not receive adequate training to address sexual concerns of their elder patients.

These findings agree with a previous study conducted in UK reported that geriatricians generally fail to take a sexual history from their patients. The barriers affecting the communication about sexual topics were embarrassment, being irrelevant, being inappropriate, and fear that patient may feel offended (12).

In this survey, the most common barriers were the fear of the patients' impression, the presence of major comorbid health problems, and the lack of privacy during the interview in $76.8 \%$, $71.4 \%$, and $71.4 \%$ of the responses, respectively.

In another study performed in Brazil, the main reasons for not obtaining a sexual history were the lack of time, fear of embarrassing the patient, and feelings of technical inaptitude (3).

Another important factor that may affect geriatricians' attitudes towards sexual history taking is proper training. About one third of our sample considered themselves properly trained to address sexual issues. In Egypt, like many other countries, the teaching of sexual health to medical undergraduates has not been consistent (13). Moreover, the training in sexual history taking and sexual health assessment and treatment remains inadequate for physicians (14). Thus, creating a uniform and standardized sexual health education program that provides geriatricians with the needed skills to address older adults sexual concerns need to be promoted.

Furthermore, we found that $18(32.14 \%)$ of the respondents underestimated the prevalence of sexual problems in older adults and 19 (33.95\%) of them reported that in their opinion older adults are not sexually active. This gap of knowledge may be attributed to underreporting of sexual issues in this age group.

In this study, interviewing a patient of opposite gender, low educational level, and low social class were perceived difficult by $71.4 \%, 67.9 \%$, and $60.7 \%$ of the respondents, respectively.
The patients' education and social status affected the attitudes of female geriatricians and the consultants.

\section{Study Limitations}

This study has limitations, one being the small sample size, which is due to non-popularity of geriatric specialty in Egypt, as well as, the low response rates, which may result in non-response bias. Two, the survey did not address the patient related barriers for discussing sexuality.

\section{Conclusion}

Many geriatricians in Egypt ignore the proactive sexual history taking due to lack of training, time pressure and personal bias. The findings of our study provide information allowing better understanding of factors affecting geriatrician's attitudes in order to improve sexually related prevention practices.

\section{Acknowledgements}

The authors thank the participants of this study.

Ethics

Ethics Committee Approval: The study methodology was reviewed and approved by the Research Review Board of the Ain Shams University Faculty of Medicine, Department of Geriatrics and Gerontology (GG-ASU-2019/18a).

Informed Consent: Informed consent was obtained from all physicians participating in this study.

Peer-review: Externally and internally peer-reviewed.

\section{Authorship Contributions}

Concept: D.R., M.M., Design: D.R., Data Collection or Processing: D.R., M.M., Analysis or Interpretation: D.R., M.M., Literature Search: D.R., M.M., Writing: D.R.

Conflict of Interest: No conflict of interest was declared by the authors.

Financial Disclosure: No financial support was provided for the research or authorship of this article.

\section{References}

1. McAuliffe $L$, Bauer $M$, Nay R. Barriers to the expression of sexuality in the older person: the role of the health professional. Int J Older People Nurs 2007;2:69-75.

2. Kalra G, Subramanyam A, Pinto C. Sexuality: desire, activity and intimacy in the elderly. Indian J Psychiatry 2011;53:300-306.

3. Cherpak GL, Santos FC. Assessment of physicians addressing sexuality in elderly patients with chronic pain. Einstein (São Paulo) 2016;14:178-184.

4. Avis NE. Sexual function and aging in men and women: community and population based studies. J Gend Specif Med 2000;3:37-41.

5. Nicolosi A, Laumann EO, Glasser DB, Moreira ED Jr, Paik A, Gingell C, Global Study of Sexual Attitudes and Behaviors Investigators' Group. Sexual 
behavior and sexual dysfunctions after age 40: The global study of sexual attitudes and behaviors. Urology 2004;64:991-997.

6. Seyam R, Albakry A, Ghobish A, Arif H, Dandash K, Rashwan H. Prevalence of erectile dysfunction and its correlates in Egypt: a community-based study. International Journal of Impotence Research 2003;15:237-245.

7. Virgolino A, Roxo L, Alarcão V. Facilitators and Barriers in Sexual History Taking, In: IsHak WW (Eds). The Textbook of Clinical Sexual Medicine. Springer International Publishing 2017, pp 53-78.

8. Lindau ST, Schumm LP, Laumann EO, Levinson W, O'Muircheartaigh CA, Waite $\amalg$. A study of sexuality and health among older adults in the United States. New Engl J Med 2007;357:762-774.

9. Hegde D, Sreedaran P, Pradeep J. Challenges in Taking Sexual History: A Qualitative Study of Indian Postgraduate Psychiatry Trainees. Indian J Psychol Med 2018;40:356-363.
10. Wimberly $\mathrm{YH}$, Hogben $\mathrm{M}$, Moore-Ruffin J, Moore SE, Fry-Johnson $\mathrm{Y}$. Sexual history-taking among primary care physicians. J Natl Med Assoc 2006;98:1924-1929.

11. Merrill JM, Laux LF, Thornby Jl. Why doctors have difficulty with sex histories. South Med J 1990;83:613-617.

12. Balami JS. Are geriatricians guilty of failure to take a sexual history? Journal of Clinical Gerontology and Geriatrics 2011;2:17-20.

13. Ariffin $F$, Chin $K L, N g$, Miskan $M$, Lee VK, Isa MR. Are medical students confident in taking a sexual history? An assessment on attitude and skills from an upper middle-income country. BMC Res Notes 2015;8:248.

14. Parish SJ, Clayton AH. Continuing Medical Education: Sexual Medicine Education: Review and Commentary (CME). The Journal of Sexual Medicine 2007;4:259-268. 